American Journal of Life Sciences
2020; 8(5): $135-143$
http://www.sciencepublishinggroup.com/j/ajls
doi: 10.11648 /j.ajls.20200805.18
ISSN: 2328 -5702 (Print); ISSN: $2328-5737$ (Online)

\title{
Maternal Mortality in Nigeria: Trend, Triggers and Implications for Sustainable Development
}

\author{
Abayomi Muftau Adesina ${ }^{1, *}$, Adegboyega Adegboye ${ }^{2}$ \\ ${ }^{1}$ Department of Economics, School of Management Technology, Federal University of Technology, Akure, Nigeria \\ ${ }^{2}$ Department of Mathematics and Computer Science, College of Natural Science, Achievers University, Owo, Nigeria
}

Email address:

drsinaabayomi@gmail.com (A. M. Adesina)

*Corresponding author

To cite this article:

Abayomi Muftau Adesina, Adegboyega Adegboye. Maternal Mortality in Nigeria: Trend, Triggers and Implications for Sustainable Development. American Journal of Life Sciences. Vol. 8, No. 5, 2020, pp. 135-143. doi: 10.11648/j.ajls.20200805.18

Received: October 23, 2019; Accepted: November 20, 2019; Published: September 3, 2020

\begin{abstract}
Sustainable development has been a major aspiration of many developing countries, including Nigeria. However, the incidence of maternal mortality in the country has elicited serious concerns from all stake holders. This paper attempts to examine the incidence of maternal mortality in Nigeria, its trend and triggers with a view to appraising its implications for sustainable development. The study utilized secondary data obtained from the World Bank's World Development Indicators 2015. The research indicates the existence of high maternal mortality in Nigeria, in spite of various government interventions in the health sector. The reasons ascribed for this situation include: poor health management; poverty, unemployment, poor access to health facilities, high illiteracy level and ignorance especially among rural dwellers, pathological causes, corruption, poor gender relations, and dearth of project management expertise. Implications for sustainable development revealed by the study include: Late/low school enrollment, absence of maternal care, increased poverty, waste of the nation's non-renewable resources, productivity impairment and slowed Gross Domestic Product growth rate. The paper therefore recommends that the government should strongly fight corruption and enforce the nine years of universal basic education, ensure comprehensive health management, craft an inclusive theory of consumption, intensify public sensitization especially for rural dwellers and hone the project management skills of health workers. Finally, government needs to intensify campaign for gender equality in order to improve female-confidence and voice in the society while also making health facilities and processes more publicfriendly with a view to facilitating access to pre- and post-natal services.
\end{abstract}

Keywords: Maternal Mortality, Wicked Problem, Sustainable Development, Nigeria

\section{Introduction}

Maternal mortality has been a major source of concern to stakeholders in the Nigerian health sector. The World Health Organization (WHO) estimates that about 536,000 women die of pregnancy-related causes annually, and close to 10 million women suffer complications related to pregnancy or child birth. In contrast to the Millennium Development Goals (MDG's) target of reducing maternal mortality ratio (MMR) by three quarters between 1990 and 2015, same was not achieved as at the end of 2015. According to WHO [28], in 2015 , about 830 women died daily due to complications of pregnancy and child birth, with almost all of these deaths occurring in low-resource settings while most of them were preventable. As high as 550 (or 66.27\%) of 830 daily maternal deaths occurred in Sub-Saharan Africa and 180 (or $21.69 \%$ ) deaths in Southern Asia, compared to five (or $0.60 \%$ ) in developed countries [28].

While successive Nigerian governments had formulated policies and implemented various programmes aimed at improving maternal health, maternal mortality ratio (MMR) has remained high.

In the recent years, aside increasing the number of health facilities at both the federal and state levels, Nigeria has invested in the training and re-training of doctors, nurses and midwives to meet the needs of the population. In spite of these efforts, the doctor-population ratio is still 1: 6000; a far cry from the WHO recommended doctor-population ratio 1:650 people [26]. 
Consequently, this paper seeks to answer the following questions: what is the trend of maternal mortality, what are the triggers of high maternal mortality, and what are it implications for sustainable development? Hence, the objectives of this paper are to: examine the trend of maternal mortality, identify the triggers of high maternal mortality as well as examine its implications for sustainable development in Nigeria. This paper would add value to the existing literature on maternal mortality with a view to promoting maternal health, and provide a good resource base for major stakeholders such as governments and policymakers to strengthen the health sector with a view to significantly facilitating sustainable development in Nigeria.

Aside this introduction, the remainder of this paper is organized as follows: section two covers conceptual/theoretical framework and literature review while section three deals with the methodology of the study. The next section examines the trend of maternal mortality, the causes of high maternal mortality as well as its implications for sustainable development in Nigeria. Section five concludes the paper.

\section{Conceptual / Theoretical Framework and Literature Review}

This section is discussed under two subsections as follows:

\subsection{Conceptual and Theoretical Framework}

This subsection is discussed under the following subheadings:

\subsubsection{Conceptual Framework}

The World Health Organization [27] defines maternal mortality as "death of a woman while pregnant or within 42 days of termination of pregnancy, irrespective of the duration and site of pregnancy, from any cause related to or aggravated by the pregnancy or its management, but not from accidental or incidental causes".

According to World Commission on Environment and Development otherwise referred to as the Brundt land Commission (1987), sustainable development is defined as the kind of development that meets the needs of the present generation without compromising the ability of future generations to meet their own needs. Hence, this definition emphasizes intergenerational equity. Concept is defined as the pattern of social and structural economic transformation that optimizes available societal benefits in the present without jeopardizing the likely potentials for similar benefits in future [16]. Although achieving development is not an easy task, it is however more demanding to sustain it. This brings us to the concept of sustainable development.

Also, concept is defined as a development strategy that manages all assets, natural and human resources as well as financial and physical assets, for increasing long-term health and well-being [20].

The issue of maternal mortality is a wicked problem in
Nigeria and has strong implications for sustainable development. A wicked problem can be described as a problem that is difficult or impossible to solve because of incomplete, contradictory and changing requirements that are often difficult to recognize. The use of the term "wicked" here has come to denote resistance to resolution rather than evil [5]. Rittel and Webber [21] formally described the concept of wicked problems in a treatise, contrasting wicked problems with relatively "tame", soluble problems in mathematics, chess or puzzle solving.

A number of researchers, multilateral agencies and scholars have expressed interest in the relationship between women and development, which has evolved over time. The term "women in development" (WID) is an approach to development projects that emerged in the 1970's calling for treatment of women's issues in development projects [25]. The term was coined by a Washington-based network of female development professionals (Tinker, 1990) who challenged the "trickle down" effect of development as it was observed that rather than being 'better off' as a result of development projects, women had always been "worse-off". Consequently, United Nations Development Programme (UNDP) established a special division for women in Development, promoting concrete action to ensure that women participate in UNDP projects [2]. This involves how women could benefit and how their status could be improved as a result of development projects. In the late seventies, "women and development" (WAD) became more prominent and this approach recognized the roles of women in development. Further, researchers and scholars observed that this discourse should go beyond women's roles and should also include gender relations. Thus, "Gender and Development" (GAD) emerged. This promotes gender equality and emphasizes giving voice to the voiceless women as well as providing equal opportunities for males and females. According to Van [24], GAD proposed more emphasis on gender relations rather seeing women's issues in isolation.

\subsubsection{Theoretical Framework}

Momentum Theory incorporates ideas from Newton's Second Law of motion and eight other theories such as the Health Belief model, the Theory of Planned Behavior, the Trans theoretical model, Ecological Systems Theory, etc [19].

This theory is called Momentum Theory because most behavioural change (whether it is to modify an unhealthy behavior or to add a health-promoting behaviour to one's life) requires substantial momentum and initial effort to get the ball rolling [20]. The theory argues that an engrained habit patterns have a self-propelling nature, an ease of action associated with the momentum, which once established, carries you along in a set direction or trajectory.

According to Repetto [20], assumptions of Momentum Theory include:

a) Health is a habit pattern that is shaped by one's daily activities, cultural background, family history, past experience, environment, economic situation, and future 
hopes;

b) A substantial amount of effort is required to adopt any new habit pattern;

c) Both external and internal forces motivate change;

d) Both pleasure and fear motivate behavioral change;

e) Habit patterns can be conscious or unconscious, health promoting or detrimental to health; and,

f) Sustained momentum requires balance between physical, mental, social, psychological, and spiritual factors.

According to this theory, a number of forces can either be a roadblock or an impetus to change depending on the person and their cultural, economic, environmental or family background. Therefore, change must begin with a thorough discussion of the person's or the community's history. Factors identified by the theory that can be either a roadblock or an incentive include: engrained family patterns, cultural patterns, or learned behavioral patterns; the perceived level of control over the given behavior; the perceived threat (susceptibility and severity) associated with a particular health pattern that is being targeted; the perceived health status of the person/community's developmental stage of life; the person's or community's narrative understanding (selfimage developed over time) and how it is shaped by the given health pattern; unintended consequences of changing (side effects); and cultural, social, or gender-based norms and / or roles.

\subsection{Literature Review}

While Nigerians cherish good health for their families and other relations, they dread maternal mortality than child mortality. For instance, if a pregnant woman loses a baby at birth, she is counseled to take solace in the fact that "it is the content that is lost as the gourd is not broken" meaning that the mother can easily conceive and produce a replacement! Adverse geographical landscape also increases the risk of carrying a baby to parturition in Nigeria as the tropical climate harbors a lot of parasites capable of causing pathological problems for the mother.

Research reports indicate that Africa accounts for the highest burden of mortality among women and children in the world $[23,24]$. One of the factors responsible for this is inadequate health personnel. For instance, the doctorpopulation ratio in 24 of the 44 nations in sub-Saharan African was estimated at 10 doctors to 100,000 people as reported by WHO [26].

According to WHO [30], globally, about 500,000 women die annually due to child birth and every minute a woman dies in child birth. Some researchers and IMF [9] have attributed high maternal mortality to a combination of factors such as a pregnant woman's decision to attend ante natal clinics but choose to deliver in the "comfort" of her home, at a church or by a traditional birth attendant.

The gap of maternal deaths between rich and poor countries is wide with 99 percent of these deaths occurring in the developing world. Maternal death statistics have been unfairly skewed against Africa in general and Nigeria, in particular. For instance, out of the 49 countries which record highest maternal deaths, 34 of these countries are in Sub Saharan Africa, where one woman in 16 dies from pregnancy or childbirth compared to 1 in 2800 in the developing world according to Amankwah [4]. Furthermore, conjectured why Sub-Saharan Africa, which constitutes 11 percent of the world's population, contributed 50 percent of to global maternal deaths annually as at 2014. He also stated that Nigeria accounted for $25 \%$ of maternal, new born and child deaths in Sub-Saharan Africa in 2014 [3].

Monitoring maternal mortality has been a great challenge due to poor reporting and inadequate metrics and methods for measuring actual death rates. Obtaining the actual mortality rate is difficult as only 31 percent of women deliver in government recognized health facilities as reported by Marchie [11].

According to WHO [28], the number of women dying due to complications during pregnancy and child birth has decreased by 43 percent from an estimated 532,000 in 1990 to 303,000 in 2015 . While the progress is noteworthy, the annual rate of decline was less than half of what was required to achieve the Millennium Development Goal (MDG) target of reducing the maternal mortality ratio by 75 percent between 1990 and 2015 WHO [28].

According to Marchie [11], the major reported causes of maternal deaths in developing world are: severe maternal bleeding, infections, obstructed or prolonged labor, unsafe abortion and hypertensive disorders of pregnancy, especially eclampsia. According to a United Nations Children's Fund (UNICEF) report, some of the major triggers of maternal mortality in Nigeria include haemorrage, obstructed labour, puerperal infection, malaria and complicated abortions.

A number of experts have suggested that haemorrage has historically been over reported while puerperal sepsis is always under reported probably due to health workers' fear of being sanctioned [8].

According to Okonofua [15] research results in Nigeria have reported puerperal sepsis as accounting for 12 percent of maternal deaths in Nigeria and that till date, little is known about the background hospital factors that predispose pregnant women to puerperal infection that leads to mortality. Accordant to Hanson [7] Perhaps, one of the most worrisome is a category of women who never attended ante natal clinics but forced to visit the hospital as emergency cases with varied degrees of complications.

Researchers aver that there exists a correlation between a country's GDP and maternal mortality ratio. This, they argued, is responsible for the low MMR in developed countries vis-à-vis developing countries. It is presumed that women who have the wherewithal in rich countries are able to afford necessary quality medical facilities when compared to women in poor countries. For instance, the United States of America, which has the highest GDP in the world in 2005, spent the highest amount on health in terms of healthcare per capita, and hence, had a MMR of 17 per 100,000 live births in the same year while Nigeria which had the 47th highest GDP in the world spent about US\$62.00 per capita and had a 
MMR of 800 per 100,000 live births within the same period $[10,31]$. It is however noteworthy that while GDP of a country is inversely related to its MMR, there are however some incongruences among developed countries [30, 10].

\section{Materials and Methods}

The data utilized in this study were obtained from Brunland Commission [31]. The data collected were analyzed using descriptive and quantitative econometric techniques. The major descriptive statistical techniques utilized include tables, mean, range, skewness, percentages, standard deviation and graph. These were principally used for analyzing the trend of maternal mortality in Nigeria during period under study.

Using the Least Squares Method, regression analysis was also used to forecast MMR in the study. To obtain an appropriate functional form, the data set was first fitted with a linear and then with quadratic functional forms while actual, fitted and regression residual graphs were generated and carefully inspected. It was observed that the quadratic functional form was more appropriate for the data as the residuals were lower and more stable in the recent years than the one obtained by fitting a linear model. Also, the gap between the fitted and actual upon using the quadratic functional form was significantly narrowed than when linear regression was used. Hence, quadratic functional form was adopted in this study as it also displayed a better explanatory power. The quadratic functional form used in the study was specified as follows:

$$
\operatorname{MMR}=\infty+\beta_{1} \mathrm{t}+\beta_{2} \mathrm{t}^{2}+\varepsilon_{\mathrm{t}}
$$

Where:

MMR = Maternal mortality Ratio;

$\infty=$ Intercept or Constant term to be estimated;

$\mathrm{t}=$ Time in years $1,2,3, \ldots 20$;

$\beta_{\mathrm{i}}=$ Parameters to be estimated.

$\varepsilon_{\mathrm{t}}=$ The randomly distributed error term with zero mean and constant variance.

The results obtained from the selected functional form was then used to forecast MMR in 2025 in order to examine the likely progress that would made and therefore make appropriate recommendations.

\section{Trend of Maternal Mortality, Triggers and Implications for Sustainable Development}

This section is discussed under distinct sub-sections as follows:

\subsection{Trend of Maternal Mortality in Nigeria}

Figure 1 shows the trend of maternal mortality in Nigeria from 1996 to 2015 .

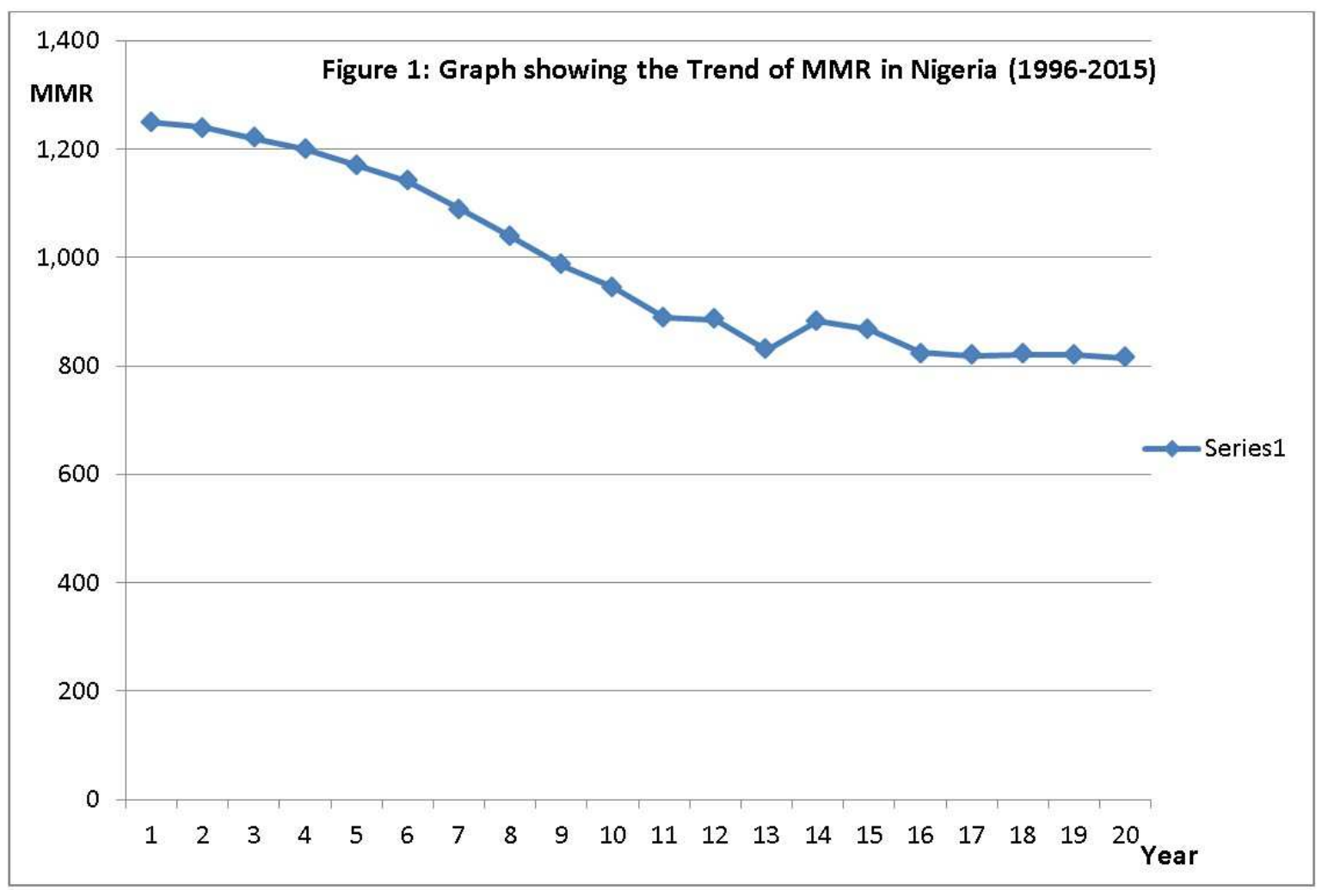

Figure 1. Graph showing the Trend of MMR in Nigeria (1996-2015).

The figure indicates that MMR consistently decline from $1,250 / 100,000$ live births in 1996 to $829 / 100,000$ live births in 2008. Subsequently, however, the MMR rose by 6.51 percent to $883 / 100,000$ live births in 2009 and dropped to 
$867 / 100,000$ live births and $824 / 100,000$ live births in 2010 and 2011 respectively. The MMR declined by 0.61 percent in 2012 to $819 / 100,000$ live births and rose by 0.24 percent to $821 / 100,000$ live births in 2013. This ratio dropped marginally by 0.12 percent and 0.73 percent to $820 / 100,000$ live births and $814 / 100,000$ live births in 2014 and 2015 respectively. The MMR of $814 / 100,000$ live births as at 2015 is still considered very high for Nigeria (Table 1).

Table 1. MMR Per 100,000 Live births in Nigeria (1996-2015).

\begin{tabular}{|c|c|c|c|c|c|c|c|c|c|c|}
\hline YEAR & 1996 & 1997 & 1998 & 1999 & 2000 & 2001 & 2002 & 2003 & 2004 & 2005 \\
\hline MMR & 1,250 & 1,240 & 1,220 & 1,200 & 1,170 & 1,140 & 1,090 & 1,040 & 986 & 946 \\
\hline YEAR & 2006 & 2007 & 2008 & 2009 & 2010 & 2011 & 2012 & 2013 & 2014 & 2015 \\
\hline MMR & 890 & 884 & 829 & 883 & 867 & 824 & 819 & 821 & 820 & 814 \\
\hline
\end{tabular}

Source: World Bank (World Development Indicators) 2016

Maternal mortality ratio ranges between 814 and 1,250 per 100,000 live births during the period under study (Table 2). The mean MMR stands at 987 per 100,000 live births with a standard deviation of 165 deaths per 100,000 live births. This implies that any year that recorded less or equal to 822 deaths per 100,000 live births was a year of significant progress in maternal mortality reduction in Nigeria while years with 1,152 or more deaths per 100,000 live births were years of substantial retardation in curbing the menace. Hence, 2012 to 2015 represent years of significant progress in maternal mortality reduction while 1996 to 2000 were years of substantial retardation in efforts geared at minimizing maternal mortality in Nigeria.

It is also worthy of note that the MMR data is fairly symmetrical since skewness statistic of 0.469 falls between 0.5 and 0.5 .

Table 2. Descriptive Statistics.

\begin{tabular}{|c|c|c|c|c|c|c|c|c|}
\hline & $\mathbf{N}$ & Range & Minimum & Maximum & Mean & Std. Deviation & Skewness & \\
\hline & Statistic & Statistic & Statistic & Statistic & Statistic & Statistic & Statistic & Std. Error \\
\hline $\begin{array}{l}\text { VAR00001 } \\
\text { Valid N (listwise) }\end{array}$ & $\begin{array}{l}20 \\
20\end{array}$ & 436.00 & 814.00 & 1250.00 & 986.6500 & 164.66818 & .469 & .512 \\
\hline
\end{tabular}

Source: Author's Calculations using SPSS Version 20

\subsubsection{Forecasting Maternal Mortality in Nigeria by 2025}

To forecast the MMR in 2025, a regression analysis was adopted. The results of the regression analysis are as shown in Table 3.

Table 3. Regression Results.

\begin{tabular}{llll}
\hline Variable & Coefficient & Std. Error & t-Statistic \\
\hline $\mathrm{C}$ & 1306.959 & 19.56207 & 66.81089 \\
$\mathrm{~T}$ & -48.95228 & 4.772260 & -10.25767 \\
$\mathrm{~T}^{\wedge} 2$ & 1.171964 & 0.242462 & 4.833592 \\
R-squared & 0.965944 & Mean dependent var & 0.0000 \\
Adjusted R-squared & 0.961938 & S. D. dependent var & 0.0000 \\
S. E. of regression & 32.12603 & Akaike info criterion & 98002 \\
Sum squared resid & 17545.39 & Schwarz criterion & 164.6682 \\
Log likelihood & -96.14691 & Hannan-Quinn criter. & 9.914691 \\
F-statistic & 241.0910 & Durbin-Watson stat & 10.06405 \\
Prob (F-statistic) & 0.000000 & & 9.943848 \\
\hline
\end{tabular}

Dependent Variable: MMR

Method: Least Squares

Date: 08/23/2020 Time: 12:46

Sample: 120

Included observations: 20

Source: Author's Calculations using EViews 8.1

The adjusted $\mathrm{R}^{2}$ of 96.2 percent indicates that about 96 percent of MMR is explained by time measured in years. Prob (F-statistic) of 0.000000 indicates that the model is significant at $1 \%$ level.

The regression resultsindicate that period $(\mathrm{t})$ in years as well as $\mathrm{t}$ squared significantly influence maternal mortality rate at $1 \%$ level of significance. A forecast of MMR in Nigeria by 2025 , going by past performance, indicates that maternal deaths would be about 893 deaths per 100,000 live births, which is still very high to the extent of continuing to impair sustainable development in Nigeria. The implication of the above analysis is that time is of essence in combating maternal mortality in Nigeria and government needs to overhaul her strategies with a view to drastically minimizing MMR.

\subsubsection{Triggers of Maternal Mortality in Nigeria}

Triggers of maternal mortality in Nigeria are discussed 
under the following headings:

\subsubsection{Poverty}

Poverty is a major issue in Nigeria. According to National Bureau of Statistics, NBS [14] the poverty incidence in Nigeria was estimated at about 71.5 percent of the population as at 2011. As reported by Abayomi and Omoyeni [1] severely poor people lack the most basic necessities of life to an extent that one would wonder how they manage to survive. While some may not even have a means of livelihood, some others eke out a living from meager economic activities that force them into a situation that can best be described as "existing but not living". In this type of situation, a pregnant woman may not have the luxury of enjoying balanced diet. This may result in her inability to access adequate quality medical facilities especially ante natal care. She may be therefore be compelled to seek help from cheap sources such as quacks and spiritual homes.

\subsubsection{Illiteracy and Ignorance}

According UNESCO Institute of Statistics (2015), Nigeria's literacy rate was put at 59.6 percent, male literacy at 69.2 percent while female literacy was estimated at 49.7 percent. This implies that there exists a high illiteracy rate, especially among the women and most of these women also wallow in sheer ignorance, which is detrimental to their, health and life, happiness and self-development.

\subsubsection{Unemployment}

According to National Bureau of Statistics [14] the formal unemployment rate in Nigeria in 2012 was estimated at $23.9 \%, 54$ percent of which were youths. Unemployment breeds poverty and inability to take adequate care of self and dependents. As long as this situation persists, it hikes the risk of maternal mortality in the country.

\subsubsection{Poor Access to Healthcare Facilities}

There are many rural settings where government healthcare facilities are absent. Owing to poverty, unemployment and sheer ignorance as well as inadequate distribution of healthcare facilities, pregnant women do not have adequate financial and physical access to healthcare facilities such as maternity, ante natal as well as postnatal care thereby increasing mortality risks.

\subsubsection{Poor Health Management}

Consensual to National Bureau of Statistics [13] no tier of government in Nigeria has strong comprehensive perspective or rolling health management plan. Hence, each administration adopts a short-sighted annual plan that is not well implemented. Also, successive administrations rubbish their predecessors' innovative healthcare programmes with a view to starting afresh which tantamount to a waste of scarce resources thereby eroding progress made by previous administrations. Poor health management also shows up in inadequate budgetary provisions made in the health sector. For instance, the 2013 budget allocation to healthcare on a per capita basis, was N1, 680 as against a WHO recommendation that government spends a minimum of N6, 908 per head, on proving healthcare services to their citizens. Thus, the out of pocket medical expenses have been very high at 65 percent of healthcare expenses in the country and this shows the precarious state of Nigeria's healthcare delivery.

\subsubsection{Pathological Causes}

Sometimes, a pregnant mother suffers from pre-existing medical conditions such as high blood pressure, hypertension, diabetes, pre-eclampsia, and so on. These conditions, if left untreated/managed could snowball into serious complications such as eclampsia and death.

\subsubsection{Poor Living/Sanitary Conditions}

High women illiteracy, ignorance and high level of poverty indicate that the tendencies for pregnant women to live in poor and non-sanitary conditions are very high. Consequently, the risk of contracting diseases and dying from preventable and/ or treatable diseases increases.

\subsubsection{Corruption}

Corruption is a cankerworm that has eaten deep into the fabrics of the society and the health sector has not been spared either. Money meant for the procurement of drugs, vaccines, machines and other medical equipment get diverted thereby depriving the intended beneficiaries of quality healthcare in the country. The poor women are those who cannot afford to seek adequate medical attention from private hospitals, thereby putting their lives on the line.

\subsubsection{Poor Gender Relations}

In Nigeria, the husband as head of the family is believed to be superior to the wife in the household. Furthermore, his decisions, especially in terms of child-bearing are final as the wife is almost voiceless. Consequently, adequate child spacing may not be achieved while the wife's life is jeopardized for carrying too many pregnancies at times up to the age of 55 years or more.

\subsubsection{Poor Project Management Skills}

There is dearth of project management skills in Nigeria. Most healthcare providers are not trained in the area of project management. These include Doctors, Nurses, Midwives, and other paramedics. Meanwhile, these skills are a sine qua non for successful healthcare project management. Therefore, most healthcare projects are haphazardly managed thereby wasting scarce national resources. Not only that, poor management of maternal health projects increases the risks of women.

\subsection{Implications of Maternal Mortality for Sustainable Development}

The implications of maternal mortality for sustainable development are described under the following sub headings:

\subsubsection{Late/Low School Enrollment}

Late/low school enrollment is both a cause as well as an implication/effect of maternal mortality in Nigeria. When a 
mother dies, the children and the entire family are psychologically affected due to the death of a loved one. They could become even depressed and may take some time to recover from the trauma. This may delay the enrollment of a child at school or may even prevent school enrollment as some children are forced to take on the role of the mother. In some extreme cases, an enrolled child may drop out of school to fend for and/ or take care of his/her siblings.

\subsubsection{Absence of Maternal Care}

Death of a mother puts a child at the mercy of an extended family member or his/her siblings who may not be able to fill the vacuum created by the mother's demise. Lack of maternal care implies that the child could be underfed or malnourished since the mother who used to be the "Home Operations Manager" is dead. Under-nutrition and malnutrition may lead to poor brain development and stunted growth in children with their welfare adversely affected. Also, most of the affected children become street urchins who disrupt peaceful co-existence of the society. Thus, the "wicked problem" of maternal mortality breeds emotionally wicked children.

\subsubsection{High Incidence of Child Labour}

High maternal mortality implies dearth of financial support to the husband and hence the surviving children constitute some form of financial burden to the living parent or guardian. In most cases, the guardian might be a poor person or someone living at the fringe of poverty. He/she is therefore compelled to engage the child in forced labour thus depriving such a child of freedom and enjoyment of childhood.

\subsubsection{Waste of the Nation's Non-Renewable Resources}

The opportunity cost of resources expended on a mother that eventually dies is high because national resources used by or expended on such a person become a waste by the time she dies. These resources would have been profitably engaged in the next best alternatives that would accrue good returns to the country. Hence, the future generations have been deprived of the wasted resources.

\subsubsection{Increased Poverty Incidence}

High maternal mortality implies the loss of a significant contributor to household income. By a wife's death, the responsibility of fending for the family rests solely on the husband, if any. This means that financially marginal families get hit below the belt by the demise of wives. Such deaths knock them below the poverty line thereby increasing poverty incidence in Nigeria.

\subsubsection{Productivity Impairment and Slowed Gross Domestic Product (GDP) Growth Rate}

The death of a loved one is traumatizing enough to adversely affect the husband's productivity for a long period of time. Thus, a high MMR implies a large population of traumatized labour whose productivity would be impaired. Prolonged productivity impairment would constitute a clog in wheel of GDP growth thereby representing a drag on the growth rate and hence national income.

\subsection{Strategies for Minimizing Maternal Mortality in Nigeria}

In view of the implications of maternal mortality for sustainable development in Nigeria, the following strategies are hereby put forward with a view to turning around the situation:

\subsubsection{Enforcement of the Universal Basic Education}

The government should enforce the nine years of universal basic education for children. Stiffer penalties should be imposed on parents and guardians who violate this policy and/ or put children in forced labour.

\subsubsection{Comprehensive Health Management}

Government should put together a strategic health development plan which should be religiously implemented. This plan should include conscious plan for consistent decline in maternal mortality which involves increased prenatal vaccinations, improved doctor and other health care workers: patient ratio, widespread distribution of heath care centres all aimed at health security. Federal and state governments must also increase health care budgetary allocations to meet WHO standards.

\subsubsection{Improved public Sensitization and Enlightenment}

Majority of the Nigerian population live in rural areas where health information is low. They need to be sensitized on the need for timely vaccinations and on how to take care of pregnant women. Adequate child spacing is also a major issue on which enlightenment should be stepped up as the buy-in of women is required in order to minimize maternal mortality.

\subsubsection{Enhancement of Project Management Skills of the Health Workers}

To facilitate success of maternal health care projects, there is need to train health care professionals including Doctors, Nurses, Midwives and other supporting health providers in health project management skills. They need to be taught how to gather health care requirements, cost and schedule management, scope management as well as health care risk management, among others.

\subsubsection{Enhancement of Gender Equality Campaign}

The three tiers of government must intensify campaign on gender equality with a view to enhancing female-confidence. The campaign would also give them voice in the society thereby making them a critical part of household decisionmaking especially in the area of number of children to have, when and how to space their children, type of pregnancy prevention methods to adopt, and so on.

\subsubsection{Ensuring Inclusive Theory of Consumption and Poverty Reduction}

To reverse under-nutrition and malnutrition, government needs to initiate policies that facilitate cheap and adequate supply of basic food items including carbohydrates, proteins, fats \& oils, vitamins and minerals with a view to making 
balanced diet within physical and financial reach of every woman.

\subsubsection{Enforcement of Stiffer Penalty Against Corruption}

Corruption should be fought to a standstill. Government should demonstrate strong political will and prosecute corruption cases to logical conclusion. It is a malaise that should be fought in all fronts; from the home, to community level, to state and national levels. Stiffer penalties against corruption should also be incorporated into Nigerian laws.

\section{Conclusion}

Maternal mortality has been a wicked problem in Nigeria for quite some time. The reasons ascribed for this situation include poor health management; high illiteracy level, gender inequality, poor sensitization of the public, especially those in the rural areas and dearth of project management expertise, among others. The implications of maternal mortality for sustainable development revealed in this study include Late/low school enrollment, absence of maternal care, waste of the nation's non-renewable resources, productivity impairment and slowed GDP growth rate. In view of the need to uproot the root causes, it is therefore pertinent that the government must overhaul its strategies such as the needs to; fight corruption strongly, enforce the nine years of universal basic education, ensure comprehensive health management, put together an inclusive theory of consumption, intensify public sensitization especially for those in rural areas, and hone the project management skills of health workers as well as intensify campaign for gender equality with a view to improving the female-confidence. All these are achievable and they must be done, because it is when Nigeria is able to achieve minimal maternal mortality ratio that the current sustainable development mirage can be turned to a miracle.

\section{References}

[1] Abayomi, M. A. and Omoyeni, J. A. (2015). The Growing Incidence of Poverty in Nigeria: Triggers, Consequences and Turnaround Strategies. Journal of Educational Research in Natural and Social Sciences (JERNASS). Vol. 1, No. 1.

[2] Agrawal, S. and Agrawal, J. C. (1996). Second Historical Survey of Women's Education in India, 1988 - 1994: Present Status, Perspective Plan, Statistical Indicators with a Global View. Concept Publishing Company.

[3] Akani, C. (2015). Right Birth, Our Birthright: A Reflection to Act Right. $116^{\text {th }}$ Inaugural Lecture of the University of Port Harcourt presented in Choba. Rivers State on Thursday, $29^{\text {th }}$ January. www.preiutiesng.com.

[4] Amankwah, A. A. (2009). Ghana: MDGs Coalition Strive to Improve Maternal Health. This Day. allafrica.com. Retrieved on $07 / 04 / 2010$.

[5] Australian Public Service Commission (2007). Tackling Wicked Problems: A Public Policy Perspective. Australian
Public Service Commission. $25^{\text {th }}$ October.

[6] Guerrier, G., Oluyide, B., Keramarou, M., \& Grais, R. (2013). High maternal and neonatal mortality rates in Northern Nigeria: an 8-month observational study. International Journal of Women's Health, 5, 495-499.

[7] Hanson, D. (2010). Data on Maternal Mortality: Historical information compiled for 14 countries (up to 200 years).

[8] Igberase, G. O., \& Ebeigbe, P. N. (2007). Maternal mortality in a rural referral hospital in the Niger Delta, Nigeria. J Obstet Gynaecol, 27 (3), 275-278.

[9] IMF. (2006). World Economic Outlook, April 2006 World Economic and Financial Surveys. Washington, DC: International Monetary Fund.

[10] Lindros A, Lukkainen A (2004). Antenatal care and maternal mortality in Nigeria. Public Health Programme - exchange to Nigeria. www.antenatal-Nigeria.pdf Retrieved on 07/04/2010.

[11] Marchie CL, Ayanwu FC (2009). Relative Contributions of Socio-Cultural Variables to The Prediction of Maternal Mortality in Edo South Senatorial District, Nigeria. Afr. J. Reprod. Health, 13 (2): 109-115.

[12] Medical World (2015). Nigeria's Health Budget: 2016 Appropriation Still Below WHO Recommendation. Posted on $31^{\text {st }}$ December, 2015 and retrieved from www.medicalworldnigeria.com.

[13] National Bureau of Statistics, NBS (2012). Nigeria Poverty Profile 2010. Abuja. NBS. Available at http://www.nigerianstat.gov.ng/uploads/latest.

[14] National Bureau of Statistics, NBS (2013). National Baseline Youth Survey Report for 2012.

[15] Okonofua, F., Okpokunu, E., Aigbogun, O., Nwandu, C., Mokwenye, C., Kanguru, L., \& Hussein, J. (2012). Assessment of infection control practices in maternity units in Southern Nigeria. Interrnational Journal for Quality in Health Care, 1-7.

[16] Pearce, D. W., Swanson, T., Brown K., and Perrings C. (1993). Economics and the Conservation of Global Biological Diversity, Global Environment Facility, World Bank, Washington DC.

[17] Pearce and Warford (1993). World Without End: Economics, Environment and Sustainable Development. New York and Oxford: Oxford University Press.

[18] Prata N, Gessessew A, Abaha AK, Holston M, Potts M (2008). Prevention of Post Partum Haemorrhage: Option for Home Births in Rural Ethiopia. Afr. J. Reprod. Health, 13 (2): 87-95.

[19] Raingruber, B. (2014). Contemporary Health Promotion in Nursing Practice. Burlington, MA: Jones \& Bartlett Learning.

[20] Repetto, R. (1986). World Enough and Time: Successful Strategies for Resource Management, Yale University Press, New Haven.

[21] Rittel, H. W. J. and Webber, M. M. (1973). "Dilemmas in a General Theory of Planning". Policy Sciences 4: 155-169. Doi: 10.1007/bf01405730. Retrieved 25 ${ }^{\text {th }}$ April, 2013.

[22] Udofia I, Okonofua F (2008). Preventing Primary Post Partum Hemorrhage in Unskilled Births in Africa. Afr. J. Reprod. Health, 12 (1): 7-9. 
[23] UNESCO Institute of Statistics [UIS] (2015). List of Countries by Literacy Rate. Retrieved from https//en.m.wikipedia.org/ on $27^{\text {th }}$ February, 2016.

[24] Van marle, K. (2006). Sex, Gender, becoming: Post-Apartheid Reflections. Pulp.

[25] Weeks, A. (2007). Maternal mortality: it's time to get political. British Journal of Obstetrics and Gynaecology, 114, 125-126.

[26] WHO (1994). International Classification of Diseases and Related Health Problems. Geneva, Switzerland: World Health Organization.

[27] WHO (2016). Global Health Observatory (GHO) Data. Retrieved from www.who.int/gho/maternal and reproductive health on 24th February, 2016.
[28] WHO. (2012). Maternal Mortality. WHO, Geneva.

[29] WHO (2007). Maternal mortality in 2005. Geneva, Switzerland: World Health Organization.

[30] WHO (2004). Maternal Mortality in 2000: Estimates Developed by WHO, UNICEF and UNFPA. Geneva, Switzerland: World Health Organisation.

[31] World Commission on Environment and Development [Brundtland Commission] (1987). Our Common Future. New York: Oxford University Press. Retrieved from Wikipedia https//en.m. wikipedia.org on $24^{\text {th }}$ February, 2016. 